\title{
Alexithymia pada Sampel Non Klinis: Keterkaitannya dengan Gaya Kelekatan
}

\section{Alexithymia in Non Clinical Samples: In Association with Attachment Styles}

\author{
Ike Meriska Rahmawati ${ }^{1}$ S Magdalena S. Halim ${ }^{2}$ \\ Magister Psikologi Profesi Klinis Dewasa \\ Universitas Katolik Indonesia Atma Jaya
}

\begin{abstract}
Alexithymia is a personality trait characterized by difficulty identifying, describing, and experiencing feelings internally. Along with other circumstances, a high level of alexithymia and insecure attachment style may increase potential of mental health problems. A cross-sectional empirical design was used to examine mean level of alexithymia in non clinical samples and the association between alexithymia and attachment styles. Participants $(\mathrm{N}=95)$ were recruited using convenience sampling. Variables were measured using Indonesian versions of Torronto Alexithymia Scale 20 and Attachment Style Questionnaire. Result showed the prevalence of Alexithymia was higher compared to some other studies with non clinical samples. Positive correlations were found between alexithymia and several attachment styles, and a negative one found with secure attachment styles. At domain level, the results provided interesting cues related to culture and emotion. Clinical implication of this study was cultural influence in individuals needs to be included in clinical observations.
\end{abstract}

Keywords: alexithymia; attachment styles; culture; emotion; personality

\begin{abstract}
Abstrak. Alexithymia merupakan sebuah trait kepribadian yang dicirikan dengan kesulitan mengidentifikasi, menjelaskan, dan menghayati perasaan secara internal. Bersamaan dengan kondisi lainnya, tingkat alexithymia yang tinggi dan gaya kelekatan tidak aman dapat memperbesar potensi gangguan kesehatan mental. Tujuan penelitian ini melihat gambaran tingkat alexithymia dan kemudian bagaimana hubungannya dengan gaya kelekatan. Partisipan penelitian ini 95 laki-laki dan perempuan yang berusia di atas 18 tahun dengan convienience sampling dan menggunakan kuesioner self report Bahasa Indonesia, yaitu Torronto Alexithymia Scale 20 dan Attachment Style Questionnaire. Hasil penelitian menunjukkan prevalensi tingkat alexithymia yang lebih tinggi jika dibandingkan dengan penelitian pada sampel non klinis sebelumnya. Uji korelasi menunjukkan total skor alexithymia berkorelasi negatif dengan gaya kelekatan aman dan berkorelasi positif dengan gaya kelekatan tidak aman. Pada tataran domain terdapat petunjuk menarik yang berkaitan dengan kekhasan budaya dan ekspresi emosi. Implikasi hasil penelitian pada situasi klinis adalah praktisi perlu mengamati klien secara utuh dengan konteks yang meliputinya.
\end{abstract}

Kata kunci: alexithymia; budaya; emosi; gaya kelekatan; kepribadian

Istilah alexithymia pertama-tama muncul untuk menggambarkan gejala-gejala yang tampak pada banyak pasien psikosimatik yang ditangani oleh Sifneos (1996) sebagai seorang psikiater. Pasien-pasien ini sangat sulit untuk diajak mendalami pengalaman

\footnotetext{
${ }^{1}$ Korespondensi mengenai artikel ini dapat melalui: ike.meriska@gmail.com
} 
emosionalnya, ceritanya terbatas pada pengungkapan fakta-fakta tanpa penghayatan personal. Emosi yang muncul bisa jadi sangat minim, juga bisa sangat meluapluap (Sifneos, 1996). Namun emosi-emosi tersebut terjadi di luar kendali mereka, di luar kesadaran mereka. Saat ini definisi alexithymia telah disepakati sebagai (1) kesulitan mengidentifikasikan perasaan dan membedakan antara perasaan dan sensasi tubuh akan gairah (arousal) emosi; (2) kesulitan menjelaskan perasaan kepada orang lain; (3) keterbatasan dalam proses imajinasi, yang terwujud dalam kurangnya fantasi; dan (4) gaya kognisi yang berorientasi pada stimulus eksternal (Nemiah, Freyberger \& Sifneos, 1976; Taylor, 1994; Taylor, Bagby, \& Parker, 1999). Dalam penelitian ini, alexithymia diamati sebagai sebuah hasil dari sejarah perkembangan hidup individu, sebagai sebuah trait kepribadian.

Alexithymia merupakan sebuah disregulasi emosi. Pemahaman teoritis mengenai konstruk ini menjadi sangat penting karena alexithymia tak dapat dipahami secara harafiah berdasarkan etiologi katanya saja. Lebih dalam lagi, alexithymia merupakan bentuk minimnya penghayatan subjektif terhadap pengalaman emosional. Hal ini menjadi sangat penting agar penggunaan istilah alexithymia ini dapat tepat sasaran, tidak ditempelkan secara asal kepada setiap orang yang terlihat kaku, pendiam, dan atau dingin. Tentunya pelabelan seperti ini bertentangan dengan usaha WHO yang hendak terus menekan medikalisasi dan institusionalisasi dalam penanganan kesehatan mental (WHO, 2013).

Dari poin ini, menjadi menarik bagaimana konstruk ini seharusnya diamati dan dipahami dalam konteks budaya berbeda, misalnya di budaya kolektif seperti di Indonesia. Di negara- negara Asia dan khususnya yang masyarakatnya bersifat kolektif, sosialisasi emosi dipenuhi dengan inhibisi, seperti ekspresi emosi baik positif maupun negatif tidak didorong untuk ditunjukkan, pendekatan yang dilakukan orang tua kepada anak cenderung menuntut kepatuhan tanpa menghiraukan kondisi emosional anak, dan penghayatan individu yang tidak terlalu dihargai (Raguram, Weiss, Channabasavanna, \& Devins, 1996). Penelitian adaptasi alat ukur kepribadian NEO PI-R yang dilakukan oleh Halim, Derksen dan Van der Staak (2004) menemukan profil partisipan Indonesia yang tertutup, konservatif, dan konformis. Tampak bahwa orang Indonesia cenderung tidak menampilkan emosi spontannya, yang sepenuhnya, dalam rangka bersikap sopan dan berusaha menghindari konflik.

Sebagai sebuah hasil dari perkembangan hidup seseorang, maka alexithymia juga terkait dengan gaya kelekatan yang terbentuk dari awal masa kehidupan seseorang. Regulasi yang adekuat akan lebih dapat berkembang jika orang tua dapat menangkap dengan tepat ekspresi emosi atau kebutuhan sang anak (Taylor et al., 1999). Pada tahap perkembangan awal anak membutuhkan peran aktif orang tua untuk melabel dan meregulasi emosi yang ia alami (Thompson, 2009). Monteboracci, Codispoti, Baldaro, \& Rossi (2004) berpendapat bahwa alexithymia merupakan salah satu konsekuensi dari kegagalan kelekatan dan ikatan (bonding). Penelitian mengenai korelasi kelekatan dan alexithymia menunjukkan bahwa kedua variabel tersebut memiliki korelasi yang signifikan, khususnya kelekatan tidak aman (Besharat \& Shahidi, 2014; Fukunishi, Sei, Morita, \& Rahe, 1999; Monteboracci et al., 2004).

Kelekatan dengan orang tua tidak sekadar mengajarkan pada anak mengenai identifikasi dan mengekspresikan emosi, 
namun juga menyimpan aspek subjektif dari emosi itu sendiri; bagaimana penghayatan mengenai suatu emosi (Lemche, Klann-Delius, Koch, Joraschky, 2004). Pola yang terbentuk dari masa kecil tersebut akan cenderung menetap hingga dewasa, yang diakses melalui gaya kelekatan tertentu. Gaya kelekatan adalah skema mental dan perilaku yang paling mudah diakses serta berhubungan dengan hubungan dekat (Mikulincer \& Shaver, 2007). Skema ini biasanya akan aktif saat individu menghadapi suatu masalah dalam hidupnya (Karantzas, Feeney, \& Wilkinson, 2010).

Pemahaman mengenai alexithymia yang tepat akan membantu dalam penentuan diagnosis karena dapat memperjelas gejala-gejala yang berkaitan dengan regulasi emosi (Muller, 2000). Dalam situasi klinis, alexithymia yang dibahas di penelitian ini bukanlah sebuah diagnosis gangguan melainkan sebuah karakteristik atau fitur klinis yang dapat memperjelas penentuan diagnosis beserta terapi yang akan diberikan kepada klien. Gangguangangguan yang terkait dengan alexithymia antara lain kesulitan mengelola stres dan lebih mudah frustrasi (Bouchard, 2008; Mallinckrodt \& Wei, 2005; Posse, Hällström, Backenroth-Ohsako, 2002; Sullivan, Camic \& Brown, 2015), masalah hubungan interpersonal (Cordova, Gee, Warren, 2005; Karakis, \& Levant, 2012; Holder, Love, Timoney, 2015), dan perilaku yang tidak terkontrol seperti penyalahgunaan zat, gangguan makan, dan perilaku agresif yang impulsif juga (Fossati et al., 2009). Selain itu, pemahaman alexithymia yang sesuai dengan konteks budaya dapat menghindarkan praktisi dari medikalisasi terhadap kekhasan ekspresi atau bentuk regulasi emosi yang berbeda dengan budaya asal konstruk ini berasal. Pada budaya kolektif ekspresi emosi yang lebih datar dan penuh inhibisi merupakan hal yang dianggap wajar, sedangkan budaya barat lebih menekankan ekspresi emosi yang lebih vokal dan konfrontatif.

Pemahaman gaya kelekatan terkait dengan suatu gangguan juga penting dalam asesmen klinis. Penelitian yang dilakukan Briere, Runtz, Eadie, Bigras, Godbout (2017) menjelaskan bahwa gaya kelekatan tidak aman menjadi salah satu faktor yang memiliki efek signifikan terhadap pembentukan simtom patologis pada individu-individu yang mengalami pola asuh orang tua yang kurang terlibat. Gaya kelekatan, khususnya gaya kelekatan tidak aman, juga menjadi faktor risiko yang terkait dengan masalah kesehatan mental dan perilaku-perilaku maladaptif dalam kehidupan sehari-hari (Beauchamp, Martineau, Gagnon, 2016; Besharat \& Shahidi, 2014; Palitsky, Mota, Afifi, Downs \& Sareen, 2013).

Tampak bahwa tingkat alexithymia yang tinggi dan gaya kelekatan tidak aman yang dominan merupakan faktor yang dapat memperbesar potensi individu mengalami gangguan psikologis. Dengan pemahaman yang lebih baik mengenai kedua konstruk ini diharapkan intervensi pada penangangan kasus-kasus psikologis bisa lebih berorientasi pada regulasi emosi dan kelekatan. Setelah kajian yang peneliti lakukan, peneliti belum menemukan gambaran mengenai tingkat prevalensi alexithymia dalam konteks budaya Indonesia, maka peneliti akan terlebih dahulu meneliti gambaran mengenai tingkat alexithymia sebelum melakukan pengujian keterkaitan antar gaya kelekatan dan tingkat alexithymia. Hipotesis penelitian ini adalah terdapat hubungan yang signifikan antara domain-domain pada gaya kelekatan dengan domain-domain pada alexithymia pada sampel non-klinis. 


\section{Metode}

\section{Partisipan}

Partisipan berasal dari masyarakat umum yang memenuhi kriteria peneliti. Kriteria yang harus dipenuhi partisipan adalah berusia di atas 18 tahun, berpendidikan minimal setingkat SMP, tidak mengalami gangguan otak organik, dan merupakan keturunan suku bangsa yang ada di Indonesia, yang tinggal menetap di Indonesia dan tumbuh besar di Indonesia. Jumlah partisipan dalam penelitian ini adalah 95 orang, dengan proporsi $57 \%$ berjenis kelamin laki-laki dan $43 \%$ perempuan. Sebagian besar usia partisipan tersebar di rentang dewasa awal dan madya dengan rata-rata usia 34.87 tahun $(S D=12.21)$. Sebanyak $49.5 \%$ partisipan merupakan lulusan SMP - Diploma dan sebanyak $50.6 \%$ partisipan berpendidikan Sarjana Doktoral. Sedangkan kelompok suku terbanyak dalam penelitian ini adalah suku Jawa $(41.1 \%)$, Kelompok suku lainnya memiliki persentasi yang jauh lebih kecil, Batak (11.6\%), Betawi ( $12.6 \%)$, Sunda (8.4\%), Tionghoa (5.3\%), Maluku (5.3\%), Campuran (5.3\%), Padang (4.2), Palembang $(2.1 \%)$, Manado $(1.1 \%)$ dan tidak mengisi (3.2\%). Semua partisipan telah diberikan informed consent dan menerima suvenir setelah mengisi kuesioner.

Alat ukur yang digunakan dalam penelitian ini adalah dua kuesioner self report, yaitu Torronto Alexithymia Scale 20 (TAS 20; Taylor, Bagby, \& Parker, 1999) versi Bahasa Indonesia yang telah diadaptasi oleh peneliti dan Attachment Style Questionnaire versi Bahasa Indonesia (ASQ; Dewi et al., 2016).

Torronto Alexithymia Scale 20 versi Bahasa Indonesia

TAS-20 merupakan alat ukur self-report, setiap aitemnya dinilai dalam skala Likert dari 1 untuk sangat tidak setuju sampai 5 untuk sangat setuju. Alat ukur ini terdiri dari 20 aitem, dengan 5 aitem bersifat unfavorable. Semakin tinggi skor mengindikasikan level alexithymia yang lebih tinggi, total skor terbentang antara 20 dan 100. Dalam versi Bahasa Inggris, cut off score telah disusun secara empiris, total skor 60 mengindikasi alexithymia yang tinggi sedangkan skor kurang dari 52 dinilai sebagai tidak ada indikasi alexithymia (Zhu, Yi, Yao, Ryder, Taylor \& Bagby, 2007). TAS 20 memiliki tiga subskala yaitu Difficulty identifying feelings and bodily sensations (DIF, terdiri dari 7 aitem, aitem-aitem ini merepresentasikan kesulitan mengidentifikasi emosi dan membedakannya dengan gejala fisiologis), Difficulty Describing Feeling (DDF, terdiri dari lima aitem, subskala ini merepresentasikan kesulitan mengartikulasikan perasaan kepada orang lain), Externally Oriented Thinking (EOT, terdiri dari 8 aitem, aitemaitem ini merepresentasikan gaya kognitif yang terikat dengan stimulus-stimulus eksternal). TAS-20 memiliki koefisien internal consistency (Cronbach's alpha) .81 dan reabilitas .77 dengan test-retest dalam waktu tiga minggu (Bagby, Parker, Taylor, 1994).

Untuk versi adaptasi Bahasa Indonesia, peneliti melakukan proses adaptasi back and forward translation dengan seizin penulis alat ukur (Taylor, komunikasi pribadi, 14 Desember 2016). Setelah itu peneliti melakukan uji confirmatory factor analysis menggunakan software LISREL 8.54 dengan jumlah partisipan sebanyak 209 partisipan yang berbeda dengan sampel penelitian ini. Hasil uji statistik menunjukkan bahwa alat ukur ini valid untuk digunakan dalam konteks Indonesia.

Alat ukur TAS-20 yang telah diadaptasi ke dalam bahasa Indonesia memiliki koefisien Cronbach Alpha sebesar .82 
untuk keseluruhan alat ukur. Sedangkan Cronbach Alpha untuk setiap domain adalah .85 untuk DIF, .78 untuk DDF, dan .40 untuk EOT. Tiap domain memiliki koefisien internal consistency sebesar DIF (.56 - .67), DDF (.46 - .64), EOT (.23 - .62). Faktor analisis yang dilakukan dengan LISREL menunjukkan bahwa setiap domain lolos atau modelnya dikatakan fit dalam uji unidimensional dan model tiga faktor fit pada first order. Maka alat ukur TAS-20 ini diukur dengan skor per domain.

\section{Attachment Style Questionnaire versi Bahasa Indonesia}

ASQ pertama kali dikembangkan oleh Feeney, Noller, dan Hanrahan pada 1994 (Karantzas et al., 2010), yang mengacu pada teori dasar kelekatan dalam hubungan dekat menurut Bowlby dan Ainsworth. Attachment Style Questionnaire (ASQ) terdiri dari 40 butir soal serta lima dimensi, yaitu Confidence, Discomfort with Closeness, Relationship as Secondary, Need for Approval dan Preoccupation with Relationship. Confidence, terdiri dari 8 aitem, merupakan dimensi yang menggambarkan kelekatan aman seperti yang juga digambarkan oleh pengukuran baik kategorikal maupun dimensional. Discomfort with Closeness, terdiri dari 10 aitem, menggambarkan aspek lain dari kelekatan menghindar (avoidant). Relationship as secondary achievement, terdiri dari 7 aitem, menangkap kelekatan menolak (dismissing) menurut Bartholomew sekaligus kelekatan menghindar (avoidant) menurut Mikulincer dan Shaver. Sedangkan, Need for Approval, terdiri dari 7 aitem, menangkap ketakutan akan penolakan dan pengabaian, seperti gaya takut (fearful) yang dikemukakan Bartholomew. Terakhir, Preoccupation with
Relationship, terdiri dari 8 aitem, menggambarkan gaya yang penuh kecemasan sehingga individu menjadi sangat bergantung dan penuh tuntutan seperti kelekatan cemas (anxious) menurut Hazan dan Shaver (Karantzas et.al, 2010).

Alat ukur ini telah diadaptasi ke dalam Bahasa Indonesia dengan koefisien internal consistency .64 (Confidence), .63 (Discomfort), .51 (Need for Approval), .71 (Preoccupation), and .59 (Relationship as Secondary Achievement). Sedangkan validitas itemnya berada di rentang .42 sampai .72 (Dewi, Halim, \& Derksen, 2016).

\section{Hasil}

Statistik deskriptif pada Tabel 1 menunjukkan bahwa hasil penelitian ini tidak dapat memenuhi asumsi distribusi normal, cukup banyak skor yang berada di atas nilai rata-rata. Dengan persebaran tersebut, kategorisasi skor dilakukan dengan transformasi non linier ke dalam $t$-score. Skor dikategorikan ke dalam lima kelompok, yaitu rendah, rata-rata bawah, rata-rata, rata-rata atas, dan tinggi. Gambar 1 menunjukkan bahwa pada penelitian ini terdapat $19 \%$ partisipan yang tergolong memiliki tingkat alexithymia yang tinggi. Jika dibandingkan dengan batasan skor pada versi TAS-20 versi aslinya, yaitu skor total $\geq 61$ untuk kategori tinggi, hasil penelitian ini menunjukkan bahwa Indonesia memiliki batasan skor yang lebih rendah untuk kategori tinggi, yaitu $\geq 57$. Perbedaan sebanyak tiga poin ini mengindikasikan bahwa ada kecenderungan tingkat alexithymia yang lebih tinggi pada sampel non-klinis pada penelitian ini. 
Tabel 1

Statistik deskriptif domain alexithymia yang diukur dengan TAS-20

\begin{tabular}{lccccc}
\hline \multicolumn{1}{c}{ Alexithymia } & Mean & SD & Median & Modus & Rentang Skor \\
\hline $\begin{array}{l}\text { Difficulty Identifiying } \\
\text { Feelings }\end{array}$ & 16.40 & 5.38 & 15 & 14 & $7-32$ \\
Difficulty Describing Feelings & 13.04 & 3.48 & 13 & 12 & $5-21$ \\
Externally Oriented Thinking & 18.72 & 2.77 & 19 & 18 & $11-28$ \\
Total Skor TAS-20 & 48.16 & 8.85 & 48 & 47 & $25-64$ \\
\hline
\end{tabular}

Uji korelasi Spearman digunakan untuk mengetahui hubungan yang terjadi antara gaya kelekatan dan alexithymia (lihat Tabel 2). Pertama, pada tataran total skor TAS-20, uji Spearman menunjukkan semua domain ASQ berkorelasi secara signifikan, kecuali domain discomfort with closeness. Korelasi negatif yang lemah terjadi antara confidence dengan total TAS-20 $\left(\mathrm{r}_{\mathrm{s}}=-.21, \mathrm{p}<\right.$ $0.05)$, yang berarti semakin dominan gaya kelekatan aman pada diri seseorang maka akan semakin rendah tingkat alexithymia yang dimilikinya. Sedangkan korelasi positif yang moderat terjadi dengan need for approval $\left(\mathrm{r}_{\mathrm{s}}=.42, \mathrm{p}<0.05\right)$, preoccupation with relationship $\left(\mathrm{r}_{\mathrm{s}}=.37, \mathrm{p}<0.05\right)$, dan relationship as secondary $\left(\mathrm{r}_{\mathrm{s}}=.45, \mathrm{p}<0.05\right)$. Semakin dominan gaya kelekatan takut, cemas, dan atau menolak-menghindar (dismissingavoidant) pada diri seseorang maka semakin tinggi pula kecenderungan tingkat alexithymianya. Secara umum hasil pada penelitian ini menunjukan hubungan yang relatif lebih kuat terjadi antara gaya kelekatan tidak aman dengan alexithymia. Semakin dominan gaya kelekatan tidak aman pada diri seseorang maka semakin tinggi tingkat alexithymianya.

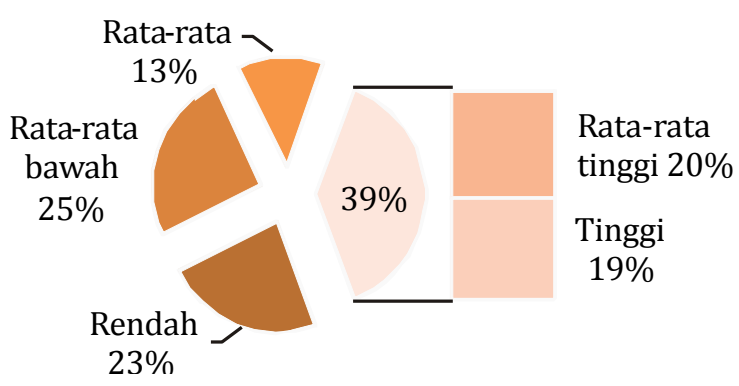

Gambar 1. Persentase Kategori Tingkat Alexithymia dengan Skor Total TAS-20 $(\mathrm{N}=95)$.

Tabel 2

Korelasi spearman antara gaya kelekatan dan alexithymia ( $\mathrm{N}=95)$.

\begin{tabular}{lcccc}
\hline \multirow{2}{*}{ ASQ } & \multicolumn{4}{c}{ TAS-20 } \\
\cline { 2 - 5 } & DIF & DDF & EOT & Total Skor \\
\hline Confidence & -0.15 & $-.32^{* *}$ & -0.07 & $-.21^{*}$ \\
Discomfort with Closeness & 0.2 & $.20^{*}$ & -0.14 & 0.16 \\
Need for Approval & $.53^{* *}$ & $.23^{*}$ & 0.04 & $.42^{* *}$ \\
Preoccupation with Relationship & $.43^{* *}$ & $.29^{* *}$ & -0.05 & $.37^{* *}$ \\
Relationship as Secondary & $.44^{* *}$ & $.34^{* *}$ & $.21^{*}$ & $.45^{* *}$ \\
\hline
\end{tabular}

** Signifikan pada level 0.01, signifikan pada level 0.05

Catatan: DIF, Difficulty Identifying Feelings and Bodily Sensations; DDF, Difficulty Describing Feelings; EOT, Externally Oriented Thinking. 
Ditemukan beberapa hal pada tataran domain, yaitu korelasi antara gaya kelekatan aman dan menghindar hanya terjadi dengan kesulitan menjelaskan perasaan (DDF), korelasi kuat hingga moderat terjadi antara gaya kelekatan tidak aman (takut, cemas, menolak-menghindar) dengan kesulitan mengidentifikasi perasaan (DIF), semua gaya kelekatan berkorelasi secara signifikan dengan kesulitan menjelaskan perasaan (DDF), dan hanya gaya kelekatan menolakmenghindar yang berkorelasi dengan gaya berpikir eksternal (EOT).

Sebagai analisis tambahan, peneliti juga melakukan uji statistik terhadap faktor demografis, seperti jenis kelamin, usia, suku dan tingkat pendidikan. Perbedaan hanya ditemukan pada tingkat pendidikan. Uji statistik Mann Whitney $U$ Test menunjukkan terdapat perbedaan tingkat seseorang mengalami kesulitan mengidentifikasi perasaan di antara tingkat pendidikan, $\mathrm{U}=821, \mathrm{p}=0.02$. Kelompok pendidikan di SMP - Diploma memiliki skor lebih tinggi pada kesulitan tersebut.

\section{Diskusi}

Pada penelitian ini terdapat sebesar 39\% partisipan yang termasuk dalam kategori di atas rata-rata, sebanyak $19 \%$ di antaranya tergolong tinggi. Jika dibandingkan dengan hasil temuan dengan penelitianpenelitan yang pernah dilakukan di beberapa negara berbeda, hasil penelitian ini menunjukkan persentase yang lebih tinggi. Dengan menggunakan cutoff score TAS-20 versi aslinya, beberapa penelitian seperti di Finlandia, prevalensi alexithymia di masyarakat umum berkisar 2\% hingga 12.8\% (Salminen, Saarijärvi, Äärelä, Toikka, \& Kauhanen, 1999; Kokkonen et al., 2001), $12 \%$ pada masyarakat umum di Australia (McGillivray, Becerra, \& Harms, 2017); 12\% pada sampel mahasiswa di Kanada (Parker, Wood, Bond, \& Shaughnessy, 2005); $17.9 \%$ pada sampel mahasiswa di Inggris (Mason, Tyson, Jones \& Potts, 2005).

Penelitian di Cina, menunjukkan hasil yang serupa dengan penelitian ini, yaitu relatif lebih tinggi dari negara-negara di Eropa (Ryder et al., 2008). Ditemukan bahwa tingkat alexithymia pada sampel di negara dengan budaya timur, seperti Cina dan Jepang, tampaknya terkait dengan perbedaan budaya yang memengaruhi gaya berpikir eksternal (EOT) (Fukunishi, Nakagawa, Nakamura, Kikuci, \& Takubo, 1997; Dere, Falk, Ryder, 2012; Dere et al., 2013). Hal ini pun juga terjadi di penelitian ini, di mana pada proses adaptasi ditemukan bahwa domain gaya berpikir eksternal tidak memiliki konsistensi yang cukup baik. Tingkat alexthymia tampaknya sangat dipengaruhi oleh penekanan gaya berpikir eksternal ketimbang identifikasi dan deskripsi emosi pada beberapa individu di budaya kolektif (Chio \& Zaroff, 2015).

Persentase yang lebih besar ini menunjukkan bahwa kecenderungan tingkat alexithymia yang tinggi lebih besar di sampel non klinis di konteks Indonesia. Adanya kontribusi dari aspek budaya dapat menjadi salah satu alasan relatif lebih tingginya tingkat alexithymia pada sampel. Pada penelitian ini pun, jumlah sampel terbesar berasal dari suku Jawa (41.1\%), maka pengaruh nilai-nilai budaya yang dipegang oleh suku ini patut dicermati lebih lanjut. Pada keluarga-keluarga suku Jawa ada suatu kecenderungan untuk sangat sedikit menampilkan emosi. Emosi yang intensif jarang ada, atau paling tidak, emosi tersebut tidak ditampilkan secara langsung. Kekeluargaan dan kerukunan adalah nilai yang sangat dijunjung tinggi, sehingga ekspresi emosi tidak ditonjolkan untuk menghindari konflik (Greetz dalam 
Subandi, 2011). Istilah "isin" atau "sungkan" merupakan kata yang sering dijadikan sebuah alasan mengapa emosi harus disembunyikan rapat-rapat. Menampilkan perasaan secara spontan dianggap tidak pantas, baik itu kecewa, putus asa, maupun gembira, rasa penuh harap (Kurniawan \& Hasanat, 2007). Ketidakpantasan tersebut biasa disebut dengan istilah "pepali ora ilok", dan mengabaikan ketidakpantasan tersebut dihayati lebih dari sekadar keharusan. Ada kepercayaan yang terkandung di dalam penghayatan tersebut, dimana seseorang yang berlaku tidak pantas dapat mendapat ganjaran yang disebut "kuwalat", "pamali" (Haryanto, 2013). Norma seperti ini pun sesungguhnya juga ada pada berbagai macam suku lain di Indonesia, di mana ekspresi emosi yang spontan kurang patut ditunjukkan terutama pada pihak yang dituakan atau dianggap otoritas. Hal ini sesuai dengan teori yang berkaitan dengan sosialisasi emosi di budaya kolektif. Sampel nonklinis pada penelitian ini mengindikasikan bahwa kedalaman emosi bukanlah hal benar-benar akrab. Teori telah menjelaskan bahwa pada budaya kolektif, emosi seringkali terabaikan sehingga tidak mencapai kesadaran yang penuh dengan penghayatan personal (Susana, 2006). Pada studi-studi sebelumnya yang dilakukan di negara dengan budaya kolektif, menunjukkan hasil yang sedikit berbeda dengan penelitian ini dimana biasanya hasil yang tinggi pada domain gaya berpikir eksternal saja (Chen, $\mathrm{Xu}$, Jing, \& Chan, 2011). Namun pada penelitian ini, domain kesulitan mengidentifikasi perasaan juga tergolong tinggi. Hal ini tampaknya terkait dengan tingkat pendidikan partisipan, pada penelitian lainnya kebanyakan partisipan merupakan mahasiswa, sedangkan pada penelitian ini terdapat $49.5 \%$ partisipan yang berpendidikan SMPDiploma. Hasil penelitian ini pun menemukan bahwa terdapat perbedaan tingkat kesulitan identifikasi perasaan antara kelompok pendidikan. Pembahasan lebih lengkap mengenai pendidikan akan dibahas selanjutnya di bagian data demografis.

Selanjutnya sebagai sebuah trait kepribadian, profil individu dengan tingkat alexithymia yang tinggi juga dapat dilihat dari alat ukur kepribadian NEO Personality Inventory Revised (NEO PI-R). Individu dengan tingkat alexithymia yang tinggi akan memiliki tingkat openness yang rendah, khususnya di facet feelings. Domain ini mengambarkan keterbukaan individu terhadap pengalaman-pengalaman baru. Individu-individu yang memiliki openness rendah merupakan individu yang memilih sesuatu yang familiar, praktis serta konkrit, dan tidak tertarik terhadap penghayatan sebuah pengalaman. Facet feelings pada domain ini menggambarkan keterbukaan individu terhadap pengalaman emosional (McCrae \& Costa, 2003). Penelitian mengenai struktur kepribadian yang diukur dengan NEO-PI-R di Indonesia menunjukkan bahwa partisipan di Indonesia memiliki skor yang rendah pada domain Openess (Halim, Derksen \& Van der Staak, 2004). Namun, jika dikaitkan dengan hasil penelitian ini, penelitian yang dilakukan oleh Halim et al. (2004) menunjukkan bahwa sampel di Indonesia pada penelitian tersebut menunjukkan openness yang lebih rendah pada facet values ketimbang facet feelings. Kedua hasil penelitian tersebut dapat memperkuat indikasi bahwa hasil penelitian yang menunjukkan prevalensi alexithymia yang tinggi di sampel non klinis ini dipengaruhi oleh kuatnya pengaruh budaya kolektif di Indonesia. Ada kecenderungan yang cukup besar bahwa pengenalan, kemampuan menjelaskan, dan gaya berpikir individu tidak sungguh-sungguh dialami sebagai 
suatu pengalaman itu sendiri, melainkan dilihat dari sudut pandang penilaian moral.

Jika dilihat pada tataran domain, tampak bahwa persentase partisipan dengan skor di atas rata-rata lebih banyak pada domain kesulitan mengidentifikasi perasaan dan gaya berpikir eksternal (DIF dan EOT sebanyak 39\%, DDF sebanyak $33.6 \%$ ). Hal ini mengindikasikan bahwa kesulitan yang dialami sampel pada penelitian adalah kesulitan mengenali emosi diri dan mendalami penghayatannya. Hasil ini bisa dipahami dengan kembali mengkaitkan hasil penelitian Halim, et. al (2004) terkait profil kepribadian sampel dengan budaya kolektif di Indonesia lebih menitikberatkan penghayatan pengalaman mereka kepada suatu nilai yang dianut, sebuah keharusan yang sudah diatur, bukan pada pengalaman itu sendiri. Peneliti melihat bahwa kemampuan menjelaskan perasaan mengandung lebih banyak aspek sosial ketimbang dua domain lainnya.

Kemampuan ini lebih mencerminkan bentuk bagaimana seseorang meregulasi ekspresi emosinya. Dalam konteks Indonesia, tentunya kemampuan ini akan sangat menyesuaikan norma sosial yang berlaku, yang artinya bahwa ekspresi emosi yang terbatas atau penuh inhibisi tidak selalu mencerminkan ketidakmampuan. Ekspresi yang diredam dan terlihat cenderung datar tersebut merupakan ekspresi emosi yang disebut ekspresi emosi high context, yaitu ekspresi emosi yang minimal namun terkait dengan konteks sekitar yang meliputinya (Gudykunts dalam Kurniawan \& Hasanat, 2007). Ekspresi ini perlu diartikan bersamaan dengan situasi saat ekspresi ini dimunculkan. Ekspresi emosi tersebut tidak langsung menggambarkan emosi yang sesungguhnya, melainkan sebuah simbol yang baru akan bermakna jika dipahami lengkap dengan konteksnya.

\section{Alexithymia dan gaya kelekatan}

Pada bagian diskusi ini, peneliti akan membahas korelasi yang terjadi antara gaya kelekatan dengan alexithymia pada tataran domain terlebih dahulu, kemudian secara keseluruhan. Pertama adalah gaya kelekatan aman. Gaya kelekatan aman merupakan hasil dari hadirnya figur kelekatan yang responsif, sehingga individu dapat mengelola kedekatannya dengan figur lain secara seimbang. Dapat dikatakan bahwa individu dengan gaya kelekatan ini memiliki kedalaman emosional yang cukup merata baik dengan orang lain ataupun dirinya sendiri. Meski tetap membutuhkan orang lain, ia juga tidak menggantungkan dirinya hanya kepada orang lain. Dari pola inilah, seseorang memiliki akses terhadap regulasi emosi yang seharusnya lebih mapan. Namun, penelitian ini menemukan bahwa gaya kelekatan aman hanya berkorelasi dengan kesulitan menjelaskan perasaan. Hasil ini sedikit berbeda dengan penelitian sebelumnya di mana gaya kelekatan berkorelasi dengan kesulitan mengidentifikasikan perasaan (Monteboracci et al., 2004). Hasil penelitian ini mengindikasikan gaya kelekatan aman tidak sepenuhnya menjamin tercapainya regulasi emosi yang lebih optimal.

Menurut peneliti, hal ini mungkin terkait dengan bentuk atau ekspresi kelekatan yang dapat berbeda di setiap budaya. Rasa aman yang diperoleh individu dari interaksi antara anak dan pengasuh utama pun dapat dimaknai dengan berbeda. Dalam budaya kolektif di mana rasa malu (shame) menjadi keutamaan dalam menghayati emosi dan keakuan dianggap tidak penting (Fontaine, Poortinga, Setiadi \& Markam, 2002; Susana, 
2006). Budaya kolektif memang mengutamakan kekeluargaan, seperti yang sebelumnya telah disebutkan, namun ikatan afeksi tersebut didasarkan pada hubungan relasi, orientasi kebersamaan, rasa saling membutuhkan, toleransi sosial, harmoni, hubungan timbal balik yang seimbang, dan rasa hutang budi (Berry, Poortinga, Segal \& Dasen dalam Dewi et al., 2016). Rasa aman yang diberikan oleh pengasuh utama pada konteks budaya setempat ini menyosialisasikan hal yang berbeda dengan konteks budaya individualis. Pada budaya kolektif, pengasuh atau figur kelekatan mendorong perkembangan individu lebih sebagai sebuah bagian kelompok, norma-norma sosial merupakan hal yang lebih diutamakan ketimbang pengenalan diri (termasuk emosi dan perasaan).

Dalam interaksi yang terjadi dengan figur kelekatan, individu dapat mempelajari pola timbal balik bagaimana emosi dan perasaan dapat diungkapkan. Jadi ketika seseorang memperoleh rasa aman dari ekspresi kelekatan yang sedemikian rupa, maka yang ia dapatkan adalah kemampuan menjelaskan perasaannya sesuai norma yang berlaku. Ekspresi dalam menjelaskan perasaan ini tak dapat jadi satu-satunya tolak ukur kedalaman penghayatan atau kemampuan identifikasi seseorang. Dalam mengidentifikasi emosi dalam diri, seseorang perlu dapat memisahkan dirinya dengan orang lain dan terbuka pada pengalaman subjektif sebagai seorang individu. Sedangkan kemampuan menjelaskan (bentuk ekspresi) bisa sangat menyesuaikan konteks budaya yang melekat. Selain itu dapat dikatakan bahwa aspek menjelaskan perasaan merupakan aspek sosial dari regulasi emosi, yang tentunya juga terkandung dalam pola interaksi antara individu dan figur kelekatan yang juga bersifat sosial.
Selanjutnya, gaya kelekatan menghindar memiliki korelasi positif yang signifikan hanya dengan kesulitan menjelaskan perasaan. Gaya kelekatan menghindar yang dapat digambarkan dalam penelitian ini memiliki aspek ketidaknyamanan (Dewi et al., 2016). Ketidaknyamanan ini tercipta karena sesungguhnya individu dengan gaya kelekatan menghindar masih mendambakan hubungan yang mendalam, hanya saja di saat yang bersamaan kedekatan juga menimbulkan rasa tidak aman pada dirinya sehingga ia tidak mengaktifkan perilaku yang berusaha mencari kedekatan. Pola ini muncul dari figur kelekatan yang memberikan banyak penolakan terhadap perilaku individu yang berusaha mendekatinya. Jika dilihat dari pola secara teoritis ini, tampak bahwa individu yang dominan pada gaya kelekatan menghindar akan lebih berpotensi untuk mengalami kesulitan menjelaskan perasaan dan belum tentu kesulitan mengidentifikasi perasaannya maupun memiliki gaya berpikir eksternal. Kesulitan menjelaskan perasaan merupakan manifestasi rasa tidak aman yang dimiliki individu yang dominan dengan gaya kelekatan ini terhadap kedekatan. Pengungkapan perasaan dapat mengaktifkan ingatannya terhadap penolakan-penolakan yang pernah ia terima dari figur kelekatannya di masa awal kehidupan, sehingga meski masih memiliki keinginan, individu-individu ini mencoba memperoleh rasa amannya dengan menahan pengungkapan emosinya.

Gaya kelekatan takut dan cemas, keduanya memiliki korelasi positif yang signifikan dengan kesulitan mengidentifikasikan dan menjelaskan perasaan. Individu yang dominan pada gaya-gaya kelekatan ini memusatkan perhatiannya terhadap orang lain. Gaya kelekatan takut memiliki pola yang dipenuhi oleh rasa 
takut akan penolakan dan pengabaian, individu yang dominan pada gaya kelekatan ini akan memusatkan perhatiannya pada penerimaan orang lain (Karantzas et al., 2010). Sedangkan gaya kelekatan cemas diliputi oleh rasa cemas berlebih yang membuat seseorang terus tergantung pada orang lain, seakan-akan tidak dapat menopang dirinya sendiri. Dapat dikatakan individu seperti ini memiliki akses yang berlebihan, mengusahakan rasa aman dengan cara yang tidak lagi seimbang. Individu-individu ini dapat menjadi sibuk memenuhi kebutuhannya akan rasa amannya sehingga mengabaikan diri subjektifnya, yang tak terikat pada orang lain.

Korelasi yang terjadi antar kedua gaya kelekatan ini dengan kesulitan mengidentifikasi dan menjelaskan perasaannya menjadi sangat tergambarkan. Individu tersebut mengembangkan strategi pengelolaan diri yang diikatkan pada penilaian orang lain, pengalaman individual yang utuh diabaikan demi rasa aman yang tak pernah berhenti mereka dambakan. Pengenalan emosi diri tidak menjadi mekanisme yang mereka munculkan karena bisa menjadi ancaman yang berujung pada penolakan maupun pengabaian. Individu-individu yang dominan pada gaya kelekatan takut dan cemas bisa berpotensi lebih sulit mengenali emosi mentahnya karena mekanisme yang mereka kembangkan selalu terkait dengan kehadiran atau pengakuan orang lain.

Terakhir, gaya kelekatan menolakmenghindar memiliki hubungan positif yang signifikan dengan semua elemen alexithymia. Individu yang dominan pada gaya kelekatan menolak-menghindar menolak keintiman dengan kepercayaan diri yang lebih tinggi, ia yakin bahwa dirinya akan jauh lebih aman dengan tidak berurusan dengan hal-hal emosional
(Carvallo \& Gabriel, 2006). Meski samasama dilandasi rasa tidak aman, orang dengan kelekatan menolak-menghindar di sini berbeda dengan gaya kelekatan menghindar yang menggambarkan aspek rasa tidak nyaman akan penolakan suatu hubungan dekat. Maksudnya adalah individu dengan gaya menghindar yang dominan menolak hubungan intim dan mendalam, tapi masih menginginkan kedekatan tersebut sehingga timbul konflik. Sedangkan gaya kelekatan cemas menggambarkan individu yang diliputi kecemasan karena mereka sangat bergantung pada orang lain dan sering merasa tidak cukup kuat menopang dirinya sendiri (Karantzas et al., 2010). Individu dengan gaya menolak-menghindar, dengan cukup percaya diri, menaruh rasa aman mereka kepada hal-hal seperti prestasi dan ambisi (Carvallo \& Gabriel, 2006).

Korelasi yang terjadi antara gaya kelekatan menolak-menghindar dan seluruh domain alexithymia cukup terjelaskan melalui pemahaman bahwa individu dengan gaya ini telah mengembangkan strategi yang mengesampingkan hal-hal emosional untuk memperoleh rasa aman. Akses terhadap keintiman yang tertutup ini juga menutup akses individu tersebut untuk mengembangkan kemampuannya mengenali emosi diri, serta mengungkapkannya. Akses terhadap alam emosional justru dianggap sebagai sesuatu yang dapat mengancam kestabilan dirinya.

Secara keseluruhan, korelasi yang terjadi antara setiap gaya kelekatan dan alexithymia menunjukkan kesamaan dengan hasil-hasil penelitian sebelumnya. Dalam penelitian ini, ditemukan bahwa gaya kelekatan aman berkorelasi negatif dengan alexithymia, sedangkan hampir semua gaya kelekatan tidak aman berkorelasi positif dengan alexithymia secara keseluruhan dan dengan domain 
kesulitan mengidentifikasi (DIF) serta menjelaskan perasaan (DDF), sejalan dengan penelitian-penelitian yang pernah dilakukan (Besharat \& Shahidi, 2014; Fukunishi, et al., 1999; Monteboracci et al., 2004). Sebagian besar individu dengan pola kelekatan tidak aman akan mengalami masalah dengan keintiman. Rasa tidak aman yang berkembang dalam diri seseorang dapat membuat individu sangat tergantung dengan orang lain atau justru menghindari keintiman. Individu-individu tersebut akan lebih sulit membangun sistem regulasi diri yang seimbang (Besharat \& Shahidi, 2014). Rasa tidak aman akan menghasilkan sebuah sistem pertahanan emosional yang membuat individu terlepas dari penghayatan emosional dalam dirinya dan bahkan tidak dapat membuat keputusan bagi dirinya sendiri. Strategi-strategi maladaptif yang terkait dengan regulasi emosi bisa muncul untuk mencapai rasa aman yang tidak pernah individu tersebut dapatkan dari pengasuh utamanya (Besharat \& Shahidi, 2014). Maka kedangkalan dalam memahami gejolak emosi dalam diri dan kesulitan menemukan kata-kata yang tepat untuk menggambarkan perasaannya sendiri ini bisa menjadi strategi maladaptif yang dikembangkan oleh individu-individu yang tidak terpenuhi rasa amannya. Individu-individu ini menggantungkan dirinya kepada figur lain yang ada di luar dirinya. Dengan hanya memusatkan penghayatan mereka sesuai dengan apa yang dianggap penting oleh figur kelekatan, mereka akan merasa lebih nyaman. Pola seperti ini terus terulang sehingga penghayatan diri pun dapat menjadi kabur, termasuk kehilangan kontak dengan alam emosi di dalam dirinya.

\section{Alexithymia dan data demografis}

Penelitian ini menemukan bahwa di antara jenis kelamin, usia, dan suku, tidak menunjukkan adanya perbedaan tingkat alexithymia. Penelitian menemukan adanya perbedaan tingkat alexithymia pada tingkat pendidikan. Tampak bahwa tingkat pendidikan yang semakin tinggi memiliki skor yang lebih rendah dalam kesulitan mengidentifikasi perasaan dan sensasi tubuh. Hal ini menunjukkan peranan penting kemampuan kognitif dalam pemahaman emosi diri. Berdasarkan kajian pustaka yang dilakukan pada tahap persiapan penelitian ini, perkembangan organisasi emosi yang diusung Lane dan Schwarz merupakan integrasi antara perkembangan kognitif menurut Piaget dengan perkembangan bahasa dan simbolisasi menurut Werner dan Kaplan. (Taylor et al., 1999). Proses kognitif adalah salah satu elemen dari emosi (Sadock \& Sadock, 2011). Alexithymia terjadi ketika perkembangan organisasi emosi itu terjebak pada level yang masih konkrit, di mana individu tidak dapat menghayatinya dengan lebih subjektif melainkan terpaku pada fakta-fakta konkrit saja (Taylor et al., 1999).

Semakin tinggi tingkat pendidikan individu maka semakin tinggi peluangnya memperoleh kekayaan bahasa untuk melabel pengalaman emosionalnya (Kauhanen, Kaplan, Julkunen, Wilson, \& Salonen, 1993) dan juga kemampuan berpikir kritis. Pada tingkat pendidikan yang lebih rendah seperti SMP, kemampuan analisis secara umum belum begitu terasah dan kekayaan bahasa pun masih terbatas jika dibandingkan dengan tingkat pendidikan seperti Sarjana. Jika dibandingkan dengan domain alexithymia lainnya, kesulitan mengidentifikasikan perasaan dan sensasi tubuh memang merupakan domain yang paling terkait 
dengan kemampuan berpikir. Dalam mengidentifikasi perasaan terkadang seseorang butuh ketajaman dan kemampuan berpikir kritis untuk mengolah stimulus yang berasal baik dalam diri sendiri maupun luar. Mengidentifikasi dalam hal ini dapat diartikan ia mampu menemukan suatu pola kesamaan maupun perbedaan untuk menyimpulkan perasaan yang ia alami. Untuk dapat mengungkapkan dan menghayati pengalaman emosinya seseorang akan melakukan evaluasi kognitif untuk lebih dulu mengenali apa yang terjadi dalam dirinya. Sedangkan saat melakukan supresi emosi, individu akan berfokus pada evaluasi perilaku yang bertujuan menghindari pengungkapan emosi tersebut (Gross dan John dalam Retnowati, Widhiarso, \& Rohmani, 2003) .

\section{Implikasi pada situasi klinis}

Berdasarkan pembahasan mengenai dinamika hubungan antara gaya kelekatan dan tingkat alexithymia ini, peneliti melihat bahwa ada potensi besar pembentukan simtom-simtom gangguan. Hasil penelitian ini mengindikasikan bahwa kelekatan aman pun tidak selalu cukup untuk mendukung pembentukan kemampuan regulasi yang optimal, tetapi gaya kelekatan tidak aman dipastikan memiliki hubungan dengan pembentukan tersebut. Sedangkan kedua variabel ini, alexithymia dan gaya kelekatan tidak aman, telah diteliti dan ditemukan bahwa keduanya merupakan faktor risiko atau fitur kepribadian yang sering ditemukan pada individu dengan gangguan kesehatan mental maupun fisik.

Implikasi dari hasil penelitian ini adalah penggunaan alat ukur alexithymia dapat diamati dari penilaian serta interpretasi skor individu di setiap domain, tidak sekadar melihat total skor. Interpretasi alat ukur ini dapat digunakan sebagai pelengkap gambaran mengenai gambaran kepribadian seseorang, tidak sekadar untuk langsung menyimpulkan gejala patologis seseorang. Pemahaman alexithymia secara umum di konteks budaya kolektif mungkin tidak dapat sekadar dipahami secara harafiah, yakni bukan sekadar kekurangan kata untuk perasaan, melainkan dilihat dari aspek regulasi emosinya. Yang dapat dipelajari dari tingkat alexithymia seseorang dalam konteks klinis seharusnya adalah seberapa jauh seseorang dapat meregulasi emosinya saat diperlukan, dan strategi adaptif seperti apa yang dapat ia usahakan untuk mengelola emosi dalam menghadapi hambatan atau tantangan dalam hidupnya.

Dengan kekhasan budaya yang berbeda penanganan orang dengan tingkat alexithymia yang tinggi sebaiknya juga tidak sekadar memaksakan untuk dapat menerapkan pola regulasi emosi yang kental dengan budaya individual. Jika ditilik dari konsep psikologi abnormal, budaya juga menjadi unsur yang sangat penting untuk dipertimbangkan dalam penentuan gejala yang dianggap patologis (N-Hoeksema, 2015). Penilaian mengenai tingkat alexithymia pada seseorang harus dilengkapi dengan kekayaan data observasi dan wawancara klinis yang tepat. Praktisi perlu mempertimbangkan bahwa individu yang menunjukkan ekspresi terbatas tidak selalu menggambarkan ketidakmampuannya dalam meregulasi emosinya. Aspek nilai yang dipegang oleh individu tersebut perlu diikutsertakan dalam proses analisis. Lo (2014) juga menemukan bahwa pada masyarakat kolektif tingkat alexithymia ini dipengaruhi oleh nilai budaya yang dianut oleh seseorang. 
Individu yang sangat terbatas dalam mengekspresikan emosinya karena pengaruh budaya yang meliputinya seharusnya akan tetap dapat menemukan pemecahan masalah yang tepat atau memiliki alternatif lain untuk mengekspresikan emosinya yang lebih dapat diterima secara normatif, namun tetap memenuhi kebutuhan emosi dalam dirinya. Sedangkan individu yang terbatas dalam mengekspresikan emosinya karena kemampuan regulasi yang kurang baik akan membentuk pemecahan masalah yang tidak adaptif sehingga masalah dapat menjadi terakumulasi dan akhirnya individu tersebut akan mudah mengalami frustrasi.

\section{Kesimpulan}

Prevalensi alexithymia yang lebih tinggi pada penelitiannya tampaknya terkait dengan budaya yang meliputi partisipan pada di penelitian ini yang mayoritas berasal dari suku Jawa. Pemahaman konstruk alexithymia sebaiknya dipahami lengkap dengan konteks budaya dan nilai yang melekat pada individu.

Hasil uji korelasi menunjukkan bahwa gaya kelekatan aman memiliki korelasi negatif dan gaya kelekatan tidak aman memiliki korelasi positif dengan dengan total skor alexithymia yang diukur dengan TAS. Hal ini sejalan dengan temuantemuan sebelumnya. Namun pada tataran domain, korelasi yang terjadi menunjukkan bahwa adanya perbedaan ekspresi kelekatan yang dialami oleh partisipan penelitian ini. Tampak bahwa di budaya kolektif yang meliputi parstisipan di penelitian ini, gaya kelekatan aman tidak sepenuhnya menjamin keleluasan individu untuk menggali kemampuan regulasi emosinya secara personal karena apa yang dianggap rasa aman adalah rasa kebersamaan dengan komunitas, bukan menonjolkan keakuan seseorang.

Analisis tambahan juga menunjukkan bahwa kemampuan seseorang dalam mengidentifikasi alam emosi dalam dirinya berkaitan dengan kemampuan kognitif. Semakin tinggi tingkat pendidikan, seseorang memiliki potensi yang lebih besar untuk memiliki ketersediaan bahasa dan kemampuan berpikir kritis untuk memahami pengalaman subjektifnya.

Saran

Keterbatasan penelitian ini adalah perolehan sampel dengan teknik convenience sampling belum dapat mewakili populasi yang seutuhnya dan mayoritas partisipan merupakan suku Jawa. Berdasarkan keterbatasan tersebut, selanjutnya dapat dilakukan penelitian untuk pengembangan alat ukur dan konstruk alexithymia dapat dilakukan terhadap sampel yang lebih representatif mewakili budaya kolektif di Indonesia secara keseluruhan.

\section{Kepustakaan}

Bagby, R. M., Parker, J. D., \& Taylor, G. J. (1994). The twenty-item Toronto Alexithymia Scale-I. Item selection and cross-validation of the factor structure. Journal of Psychosomatic Research, 38(1), 23-32. doi: 10.1016/ 0022-3999(94)90005-1

Beauchamp, G., Martineau, M., \& Gagnon, A. (2016). Examining the link between adult attachment style, employment, and academic achievement in fisrt semester higher education. Social Psychology of Education, 19(2), 367-384. doi: 10. 1007/s11218-015-9329-3

Besharat, M. A., \& Shahidi, V. (2014). Meditating role of cognitive emotion 
regulation strategies on the relationship between attachment style and alexithymia. Europe's Journal of Psychology, 10(2), 352-362. doi: 10.5964/ejop.v10i2.671

Bouchard, G. (2008). Alexithymia among students and professionals in function of disciplines. Social Behavior and Personality: An International Journal, 36(3), 303-314.

Briere, J., Runtz, M., Eadie, E., Bigras, N., \& Godbout, N. (2017). Disengaged parenting: structural equation modeling with child abuse, insecure attachment, and adult symptomatology. Child Abuse \& Neglect, 67, 260270. doi: 10.1016/j.chiabu. 2017.02.036

Carvallo, M., \& Gabriel, S. (2006). No man is an island: The need to belong and dismissing avoidant attachment style. Personality and Social Psychology Bulletin, 32(5), 697-709. doi: 10.1177/ 0146167205285451

Chen, J., Xu, T., Jing, J., \& Chan, R. C. (2011). Alexithymia and emotional regulation: A cluster analytical approach. BMC psychiatry, 11(1), 33. doi: 10.1186/1471244X-11-33.

Chio, P. H., \& Zaroff, C. M. (2015). Traditional Chinese medicinal herbal tea consumption, self-reported somatization, and alexithymia. Asia-Pacific Psychiatry, 7(2), 127-134. doi: 10.1111/ appy.12161

Cordova, J. V., Gee, C. B., \& Warren, L. Z. (2005). Emotional skillfulness in marriage: Intimacy as a mediator of the relationship between emotional skillfulness and marital satisfaction. Journal of Social and Clinical Psychology, 24(2), 218-235. doi: 10.1521/ jscp.24.2.218.62270

Dere, J., Falk, C. F., \& Ryder, A. G. (2012). Unpacking cultural differences in alexithymia: The role of cultural values among Euro-Canadian and ChineseCanadian students. Journal of CrossCultural Psychology, 43(8), 1297-1312. doi: 10. 1177/0022022111430254

Dere, J., Tang, Q., Zhu, X., Cai, L., Yao, S., \& Ryder, A. G. (2013). The cultural shaping of alexithymia: Values and externally oriented thinking in a Chinese clinical sample. Comprehensive Psychiatry, 54(4), 362-368. doi: 10.1016/j.comppsych. 2012.10.013.

Dewi, Z. L., Halim, M. S., \& Derksen, J. (2016). Attachment in context: The role of demographic factors among Indonesians from three ethnic groups. Journal of Adult Development, 23(3), 163173. doi: 10.1007/s10804-016-9232-y

Fontaine, J. R., Poortinga, Y. H., Setiadi, B., \& Markam, S. S. (2002). Cognitive structure of emotion terms in Indonesia and The Netherlands. Cognition $\mathcal{E}$ Emotion, 16(1), 61-86. doi: 10.1080/02699933014000130

Fossati, A., Acquarini, E., Feeney, J. A., Borroni, S., Grazioli, F., Giarolli, L. E., ... \& Maffei, C. (2009). Alexithymia and attachment insecurities in impulsive aggression. Attachment $\mathcal{E}$ Human Development, 11(2), 165-182. doi: 10.1080/ 14616730802625235.

Fukunishi, I., Nakagawa, T., Nakamura, H., Kikuchi, M., \& Takubo, M. (1997). Is alexithymia a culture-bound construct? Validity and reliability of the Japanese versions of the 20-item Toronto Alexithymia Scale and modified Beth Israel Hospital Psychosomatic Questionnaire. Psychological Reports, 80(3), 787-799.

Fukunishi, I., Sei, H., Morita, Y., \& Rahe, R. H. (1999). Sympathetic activity in alexithymics with mother's low care. Journal of Psychosomatic Research, 46(6), 
579-589.

Halim, M. S., Derksen, J. J. L., \& Van der Staak, C. P. F. (2004). Development of the revised NEO personality inventory for Indonesia: A preliminary study. Ongoing themes in psychology and culture (Online Edition).

Haryanto, J. T. (2013). Kontribusi ungkapan tradisional dalam membangun kerukunan beragama. Walisongo: Jurnal Penelitian Sosial Keagamaan, 21(2), 365392.

Holder, M. D., Love, A. B., \& Timoney, L. R. (2015). The poor subjective well-being associated with alexithymia is mediated by romantic relationships. Journal of Happiness Studies, 16(1), 117133. doi: 10.1007/s10902-014-9500-0

N-Hoeksema, S. (2015). Abnormal psychology. Boston: McGraw-Hill.

Karantzas, G. C., Feeney, J. A., \& Wilkinson, R. (2010). Is less more? Confirmatory factor analysis of the Attachment Style Questionnaires. Journal of Social and Personal Relationships, 27(6), 749-780. doi: 10.1177/0265407510373756

Kauhanen, J., Kaplan, G. A., Julkunen, J., Wilson, T. W., \& Salonen, J. T. (1993). Social factors in alexithymia. Comprehensive Psychiatry, 34(5), 330-335. doi: 10.1016/ 0010-440X(93)90019-Z

Karakis, E. N., \& Levant, R. F. (2012). Is normative male alexithymia associated with relationship satisfaction, fear of intimacy and communication quality among men in relationships?. The Journal of Men's Studies, 20(3), 179-186. doi: 10.3149/ jms.2003.179

Kokkonen, P., Karvonen, J. T., Veijola, J., Läksy, K., Jokelainen, J., Järvelin, M. R., et al. (2001). Prevalence and sociodemographic correlates of alexithymia in a population sample of young adults. Comprehensive Psychiatry, 42(6),
471-476. doi: 10.1053/comp.2001.27892

Kurniawan, A. P., \& Hasanat, N. U. (2007). Perbedaan ekspresi emosi pada beberapa tingkat generasi suku Jawa di Yogyakarta. Jurnal Psikologi, 34(1), 1-17. doi: 10. 22146/jpsi.7086

Lemche, E., Klann-Delius, G., Koch, R., \& Joraschky, P. (2004). Mentalizing language development in a longitudinal attachment sample: Implications for alexithymia. Psychotherapy and Psychosomatics, 73(6), 366-374. doi: $10.1159 / 000080390$

Lo, C. (2014). Cultural values and alexithymia. SAGE Open, 4(4), doi: 10.1177/ 2158244014555117.

Mason, O., Tyson, M., Jones, C., \& Potts, S. (2005). Alexithymia: Its prevalence and correlates in a British undergraduate sample. Psychology and Psychotherapy: Theory, Research and Practice, 78(1), 113125. doi: $10.1348 / 147608304 \times 21374$

McCrae, R. R., \& Costa, P. T. (2003). Personality in adulthood; A five-factor theory perspective. Guilford Press.

McGillivray, L., Becerra, R., \& Harms, C. (2017). Prevalence and demographic correlates of alexithymia: A comparison between Australian psychiatric and community samples. Journal of Clinical Psychology, 73(1), 76-87. doi: 10. 1002/jclp.22314. Epub 2016 Apr 29.

Mallinckrodt, B., \& Wei, M. (2005). Attachment, social competencies, social support, and psychological distress. Journal of Counseling Psychology, 52(3), 358. doi: 10. 1037/0022-0167.52.3.358

Mikulincer, M., \& Shaver, P. R. (2007) Attachment in adulthood: Structure, dynamics, and change. Guilford Press.

Montebarocci, O., Codispoti, M., Baldaro, B., \& Rossi, N. (2004). Adult attachment style and alexithymia. Personality and 
Individual Differences, 36(3), 499-507. doi: 10. 1016/S0191-8869(03)00110-7

Muller, R. J. (2000). When a patient has no story to tell: alexithymia. Psychiatric Times, 17(7), 137-141.

Nemiah, J. C., Freyberger, H., \& Sifneos, P. E. (1976). Alexithymia: A review of the psychosomatic process. In. 0. W. Hill (ed.) Modern trends in psychosomatic medicine (Vol. 3, pp. 430-439). London: Butterworths.

Palitsky, D., Mota, N., Afifi, T. O., Downs, A. C., \& Sareen, J. (2013). The association between adult attachment style, mental disorders, and suicidality: findings from a population-based study. The Journal of Nervous and Mental Disease, 201(7), 579-586. doi: 10.1097/NMD.0b013e31829829ab.

Parker, J. D., Wood, L. M., Bond, B. J., \& Shaughnessy, P. (2005). Alexithymia in young adulthood: A risk factor for pathological gambling. Psychotherapy and Psychosomatics, 74(1), 51-55. doi: 10.1159/000082027

Posse, M., Hällström, T., \& BackenrothOhsako, G. (2002). Alexithymia, social support, psycho-social stress and mental health in a female population. Nordic Journal of Psychiatry, 56(5), 329334. doi: 10.1080/080394802760322088

Raguram, R. D. P. M., Weiss M. G., Channabasavanna, S. M., \& Devins, G. M. (1996). Stigma, depression, and somatization in South India. American journal of Psychiatry, 153(8), 1034-1049.

Retnowati, S., Widhiarso, W., \& Rohmani, K. W. (2003). Peranan keberfungsian keluarga pada pemahaman dan pengungkapan emosi. Jurnal Psikologi, 30(2), 91-104. doi: 10.22146/jpsi.7028

Ryder, A. G., Yang, J., Zhu, X., Yao, S., Yi, J., Heine, S. J., \& Bagby, R. M. (2008). The cultural shaping of depression: Somatic symptoms in China, psychological symptoms in North America?. Journal of Abnormal Psychology, 117(2), 300. doi: 10. 1037/0021-843X.117.2.300.

Sadock, B. J., \& Sadock, V. A. (2011). Kaplan and Sadock's synopsis of psychiatry: Behavioral sciences/clinical psychiatry. Lippincott Williams \& Wilkins.

Salminen, J. K., Saarijärvi, S., Äärelä, E., Toikka, T., \& Kauhanen, J. (1999). Prevalence of alexithymia and its association with sociodemographic variables in the general population of Finland. Journal of Psychosomatic Research, 46(1), 75-82.

Sifneos, P. E. (1996). Alexithymia: past and present. The American Journal of Psychiatry, 153(7), 137.

Subandi, M. A. (2011). Family expressed emotion in a Javanese cultural context. Culture, Medicine, and Psychiatry, 35(3), 331. doi: 10.1007/s11013-011-9220-4.

Sullivan, L., Camic, P. M., \& Brown, J. S. (2015). Masculinity, alexithymia, and fear of intimacy as predictors of UK men's attitudes towards seeking professional psychological help. British Journal of Health Psychology, 20(1), 194211. doi: 10. 1111/bjhp.12089

Susana, T. (2006). Somatisasi dalam budaya kolektivis ditinjau dari pemaknaan Nelson: Kritik terhadap psikoanalisa klasik. Buletin Psikologi, 14(2). doi: 10.22146/ bpsi.7489

Taylor, G., J. (1994). The alexithymia construct: conceptualization, validation, and relationship with basic dimension of personality. New Trends in Experimental \& Clinical Psychiatry. 10(2), 61-74.

Taylor, G. J., Bagby, R. M., \& Parker, J. D. (1999). Disorders of affect regulation: Alexithymia in medical and psychiatric illness. Cambridge University Press. 


\section{ALEXITHYMIA PADA SAMPEL NON KLINIS}

Thompson, J. (2009). Emotionally dumb: An overview of alexithymia kindle edition. Soul Books.

World Health Organization (WHO). (2013). Mental Health action plan 2013-2020. Retrieved from http:// www.who.int/mental_health/ publications/action_plan /en/
Zhu, X., Yi, J., Yao, S., Ryder, A. G., Taylor, G. J., \& Bagby, R. M. (2007). Crosscultural validation of a Chinese translation of the 20-item Toronto Alexithymia Scale. Comprehensive Psychiatry, 48(5), 489-496. doi: 10.1016/j.comppsych.2007.04.007 